\title{
Bridging policy and science action boundaries: information influences on US congressional legislative key staff decision making in natural resources
}

\author{
Timothy R. Petty ${ }^{1}$ (D) John B. Gongwer ${ }^{2} \cdot$ William Schnabel $^{3}$
}

Published online: 14 February 2018

(C) The Author(s) 2018. This article is an open access publication

\begin{abstract}
This paper provides a framework to evaluate how policymakers interact with information, make decisions, and act upon policy-related information. To explore the influence of information in bridging water policy knowledge boundaries and linking policy decision making and action, the authors conducted a grounded theory study of key congressional legislative staff in the US House and Senate involved in federal water policy development and oversight. Federal legislative water policies are largely shaped and developed by senior congressional legislative staff, whose policy priorities, decisions, and actions are influenced by policy-related information. Three conceptual themes emerged from the study as common priorities for legislative staff: (1) developing trusted relationship-information networks; (2) prioritizing relevant stakeholder interests; and (3) maximizing efforts to achieve desired results. While the use of policy information is largely determined by the staff's multiple principal-agent roles, competing interests and other constraints, results of this study suggest that information quality criteria can be useful as heuristic tools for both intuitive judgments and reasoning of legislative decision makers and for transferring knowledge across science-policy action boundaries.
\end{abstract}

Key words Policy-science boundaries - Legislative decision making · Policy formation · Heuristics · Information boundaries · Water policy

Timothy R. Petty

tpetty3@alaska.edu

1 College of Engineering and Mines, University of Alaska Fairbanks, Fairbanks, AK, USA

2 Policy Research, United States Senate, Washington, DC, USA

3 Department of Civil and Environmental Engineering, Institute of Northern Engineering, University of Alaska Fairbanks, Fairbanks, AK, USA 


\section{Introduction}

This paper explores the degree to which generally assumed criteria influence policymakers' use of information in decision making and legislative action. To accomplish this, the authors conducted a grounded theory research study of key congressional legislative staff involved in federal water policy development and oversight in the US House and Senate. This study provides an interpretative lens for exploring how policymakers interact with, make decisions on, and act upon policy-related information.

Traditionally, policymakers have called upon science and other fields of knowledge to produce and disseminate useful information for sound decision making. Such information, it is argued, would improve the process by clarifying issues and choices and help decision makers successfully make the rational judgments that lead to desired outcomes (McNie 2007). However, if decision makers do not perceive the information to be relevant or useful, then simply increasing the supply of accurate scientific information does not help inform policy.

In response to the perception that research has limited influence on policy because it is neither relevant nor useful, considerable discussion has taken place over the last decade or so to identify how best to bridge the so-called divide between science and policy and make information more useful to decision makers. Discussed in a later section, results from a number of studies have indicated that information (e.g., scientific information) must be perceived by decision makers as meeting minimal thresholds of specific quality criteria in order for the information to be considered or to influence policy decisions and actions (Cash et al. 2003).

Refocusing the issue from simply providing "more and better" science to exploring how decision makers perceive the relevance and usefulness of scientific research has led to using this interpretive lens for revisiting issues of research structuring, funding, and results framing. This focus on policy utility has spawned numerous studies, calls for action, research methods, and models for science-policy interaction and decision making. Many, if not most, of these studies were written by or for scientists and specialists and were aimed at improving the shape of research, packaging research results, and crafting more effective communication in order to achieve greater influence of science on policy-making. However, despite the growing body of analytic literature and improvements, the perception persists that science continues to have relatively little impact on policy, regardless of this new focus on receptivity (Meinke et al. 2006; Bauler 2012; Lemos et al. 2012).

While a few studies have presented the issue from the perspective of policymakers, there has been a relative absence of research or writing on the complex dynamics of how the policymakers themselves process information and make decisions.

\section{Study context-water resources and the legislative process}

The water management system in the USA is distributed among different entities and jurisdictions at the federal and state levels. Numerous federal government and independent commissions, from the Gallatin Report of 1808 to the report of the National Drought Policy Commission in 2000, have studied water policy and called for reform of the costly and counterproductive fragmentation and conflict, overlap, duplication, and ultimately the lack of overall accountability for land and water use impacts (Neuman 2010; Christian-Smith et al. 2011).

Today, at the federal level, water policy related to managing or regulating water resources is created through several mechanisms, most prominently federal agencies and 
Congress. In the Executive Branch, there are more than 25 federal bureaus and agencies with regulatory authority on water issues, additional boards, and commissions with waterrelated programs and responsibilities, and over 200 separate federal directives, regulations, and laws (Gerlak 2006; Christian-Smith et al. 2011). Federal water policy, in part, consists of numerous legislative initiatives that deal with a large number of often unrelated issues and funding programs. There are more than a dozen major pieces of federal legislation related to water, and roughly 40 congressional House and Senate committees and subcommittees with various levels of oversight and policy input on diverse and often overlapping water issues (Allin 2008; Cody et al. 2012).

The legislative process grew significantly following the Legislative Reorganization Acts of 1946 and 1970, and this growing role has been mirrored in the expanding number of committees and committee staff members. Congress currently has twenty-one standing committees in the House and sixteen in the Senate, together with eight other special (or "select" or "joint") types of committees. While having leveled off in recent years, staff numbers remain comparatively high, and today exceed the 1935 staffing levels by more than 500\% (Shobe 2014).

\section{Role of senior legislative staff}

As the legislative process has grown in sophistication over the past several decades, specialized congressional staff-historically often overlooked in literature on policymaking in the legislative process - have played an increasingly dominant role in crafting policy, drafting legislative history and statutory text, and shaping the process and outcome of national legislation (Schultz Bressman and Gluck 2014).

As of September 2016, there were more than 15,000 staff in Congress. Legislative staff in both the House and Senate are generally defined by where they work and the functions they perform; these definitions roughly correspond with four main types or categories. In 2016, the breakdown of these four staff types were as follows: (1) $73 \%$ were legislative staff in the personal offices of individual members in the House and Senate; (2) $16 \%$ were staff that work in bipartisan committees (staff members answering to their respective party leadership in their committees); (3) 3\% were staff in leadership offices; and (4) $8 \%$ were staff working for congressional officers and officials, including approximately eighty nonpartisan professional staff $(0.5 \%)$ that worked in the Offices of Legislative Counsel (OLC) in the House and Senate (CRS Report No. R43946, 2016a; CRS Report No. R43947, 2016b).

This paper focuses on a small subset of senior legislative staff in personal offices and committees that work on developing legislation (excluding staff in the leadership offices and OLC staff), since most legislative initiatives and histories originate from personal offices and committees. Staff in the leadership offices are generally not involved in the drafting of legislative histories or bills, and OLC specialists generally take concepts, broad outlines and/or rough drafts provided by other sources (e.g., personal offices or committees) and serve as the primary drafters that shape the statutory texts of legislation (Schultz Bressman and Gluck 2014).

Due to a variety of constraints, members of Congress explicitly or implicitly delegate to their staffs varying degrees of autonomy and responsibility to manage their congressional duties and represent their interests in both daily operations and in critical legislative functions. Elaborated further in the Findings and Discussion section, this relationship of delegated authority has led to a number of studies that evaluate the roles and activities of congressional staff through the lens of agency theory and principal-agent models (Romzek 
2000). In these models, agents are individuals or groups who are authorized and delegated to act on behalf of another party, the principal. While most staff perform multiple principal-agent roles in the course of their duties, a relatively small number of senior or specialist staff perform a variety of complex, often overlapping, and sometimes conflicting roles in legislative development.

Several studies about the key influences on the congressional legislative drafting process confirmed the widely-held view that congressional members rarely draft legislation and/or are involved in the actual crafting of legislative texts (Nourse and Schacter 2002; Gluck and Schultz Bressman 2014; Shobe 2014). Instead, it is small groups of congressional staff that influence and draft most or all of the two primary products of the legislative process-legislative history and the bills that become enacted statutory texts. Broad policy concepts may originate from members of Congress, and legislators may initiate, sponsor and vote on the legislation, but modern statutes are largely the product of legislative staff-conceptualized by senior staff from personal offices or committees, researched by professional analysts, and drafted by nonpartisan professional legislative counsels (with initial drafts occasionally prepared by private third parties such as lobbyists), with monitoring and input from hundreds of committee staff and non-government organizations.

For staff in personal offices and committees, task and job functions vary depending on where the staff members work. Only a small percentage of personal office staff are involved in legislative development, with fewer yet involved directly in the statutory drafting process (Gluck and Schultz Bressman 2014). Many congressional members may have legislative staff who cover water resources policy-related issues, but for most of these staffers, these issues are normally only addressed when their member becomes involved in a related issue, floor debates, or votes. However, members who serve on committees related to water issues-particularly those with senior committee positions or those with strong personal or constituent interests-generally have senior legislative staff who have specialty knowledge of relevant water issues and often have experience in drafting legislation, networking, negotiating, and effectively navigating the legislative development process (Romzek and Utter 1997). In comparison with staff in personal offices, a larger percentage of committee staff are involved in the policy development process-focusing on analyzing policy proposals, drafting legislation and building coalitions in committee, and negotiating on behalf of their committees and chairs (Romzek and Utter 1996).

\section{Information and decision making}

National water policy priorities and decisions of congressional staff are influenced by competing interests, ambiguous or multiple frames of reference, and a variety of policy information sources. This information can be presented to staff from outside organizations and individuals (e.g., lobbyists, nonpartisan policy research organizations, industry groups, and other issue stakeholders), generated informally through work relationships and informal networks (friendships with other staffers, social and professional circles, etc.), enlisted upon requests from the staff or members to prepare and present data (e.g., Congressional Research Service), actively solicited (e.g., expert testimony during congressional hearings), or reside in content repositories (e.g., libraries, online data sources). Most of this information and knowledge is explicit, codified, and shared digitally or through impersonal networks and formats, but some knowledge, such as sharing of practical how-to expertise, is tacit and more easily transferred interpersonally. 
These information sources (whether institutions or other social entities) often have individually distinct practitioners, practices, values, and attributed characteristics of human information interaction (knowledge generation, processing, decision making, and implementation). Together the characteristics act as social boundaries that segment and delineate these entities. Differences in the characteristics can lead to difficulties when these entities attempt to transfer information across boundaries (Guston 1999).

The content of information transferred across boundaries, as well as the perceptions that senior legislative staff have regarding the sources of that information, not only influence staff priorities (in their principal-agent roles), but ultimately can also have a disproportionate impact on legislative voting behavior. Sabatier and Whiteman's 1985 review of studies on legislative decision making found that the traditional two-stage model of information flow is less applicable in sophisticated legislative environments like the US Congress. In the two-stage model, information flows directly from internal and external legislative information sources to "specialist legislators" (typically the chairmen and senior members of the committees with jurisdiction over the legislation being considered). Sabatier and Whiteman's alternative three-stage model (an adaptation of which is shown in Fig. 1) illustrate how information flows first from the legislative environment to personal or committee staff, who then frame and transmit this information to specialist legislators, who in turn communicate this information to "non-specialist" legislators.

Voting choice studies frequently found that non-specialist legislators rely heavily on cues from specialist legislators whom they consider knowledgeable about issues being discussed. These specialist legislators, when working in their areas of expertise, rely heavily upon and have their decision making significantly influenced by their senior legislative staff, whose activities include "monitoring and evaluating information on policy

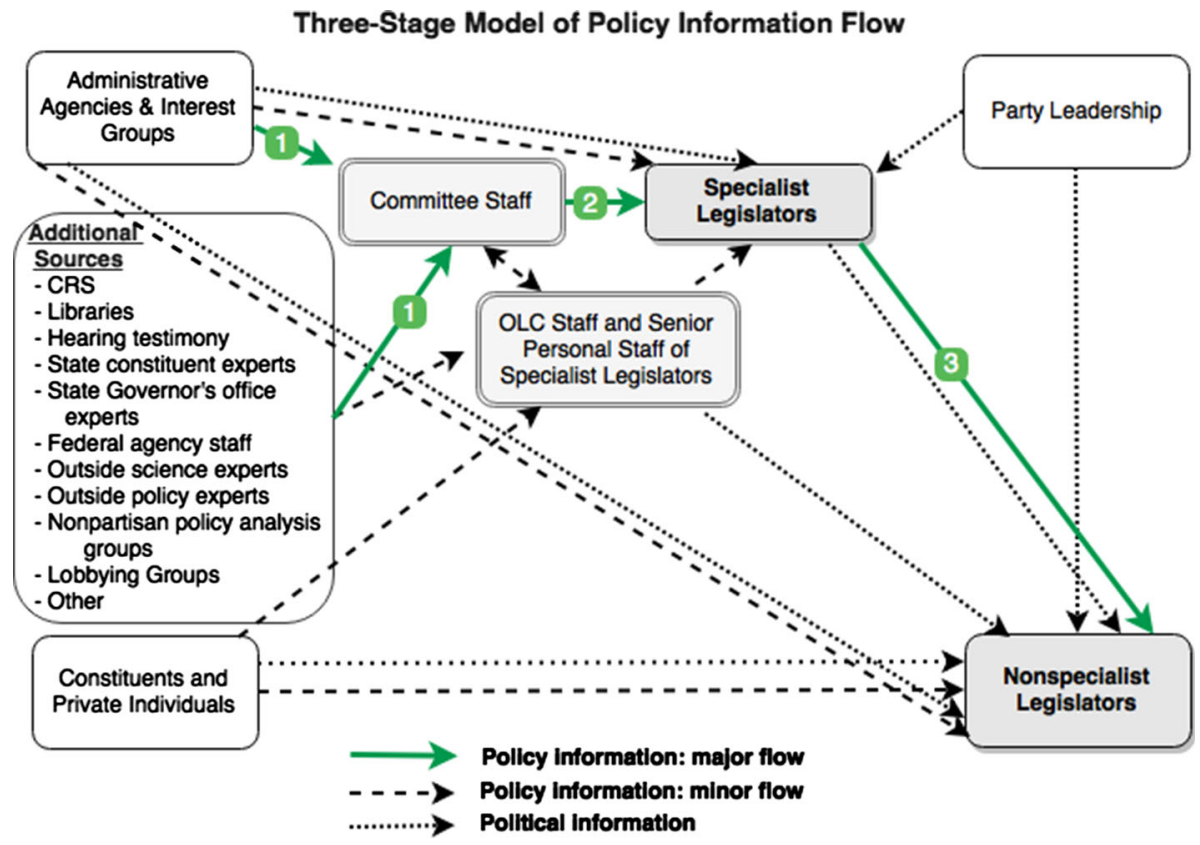

Fig. 1 Three-stage model of policy information flow. Adapted from Sabatier and Whiteman (1985), with addition of multiple congressional policy information sources 
developments, structuring legislative hearings, formulating policy alternatives, and negotiating compromises." For specialist legislators, staff are the most important source of information (Sabatier and Whiteman 1985).

\section{Framework (RCL) of information choice and utilization for legislative staff}

In their exploration of influences on policy decision making and action, a number of researchers have identified three information quality attributes generally considered necessary for bridging the information boundary and utilizing that information in policy decisions and action. These studies indicate that policymakers tend to act on policy-related information when it is perceived as relevant, credible, and legitimate (RCL) (Fig. 2) with multiple audiences (Cash et al. 2002; Clark et al. 2016). RCL is used in this study as the framework for which to create a contextual understanding.

Relevance (often referred to as salience or saliency) is understood as the degree of relation to the matter under consideration, or the significance of the information for a decision maker's choices, or the choices of a given stakeholder (Heink et al. 2015).

Credibility of knowledge, a quality often linked with or equated with the concept of believability (i.e., judgement of logical or scientific soundness), is often the focus of scientists and scholars. Information (theories, beliefs, statistical data, and facts) is perceived as credible if it meets standards and established criteria requirements of scientific plausibility and technical merit. In addition, the source of the information must be perceived or judged as believable or trustworthy. Even if information is relevant, it will tend to be ignored if not considered credible (Cash et al. 2002).

Legitimacy is an ascribed value of information regarding the degree to which the information is produced in an unbiased system that is politically and procedurally fair and is fairly representative of the views, values, and concerns of involved stakeholders, including (and perhaps most importantly) those of the decision makers. If the information is deemed relevant and credible, but is not perceived as having been produced or used in a legitimate way, it has a low probability of being used (Cash et al. 2002). This quality criterion is considered to be essential for information to transfer across science-policy boundaries and be used as "actionable knowledge" that influences policy decision making and action (Meinke et al. 2006).

There are both tensions and complementarities between these three attributes. Efforts to enhance one or more of these attributes may also increase another attribute or may create a tension and lead to a lessened perception of another attribute. The most successful efforts involve effective balancing and trade-offs where all three attributes exceed their individual thresholds of acceptability.

Fig. 2 RCL dynamic. The interrelated dynamic between the information quality criteria of relevancy, credibility and legitimacy in linking policy decisions and action

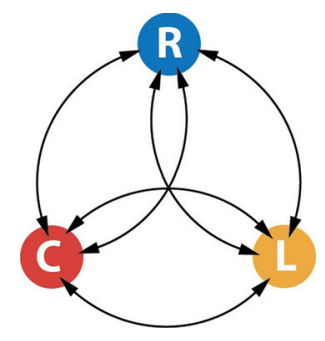


The remainder of this paper consists of: (1) Methods: research design (theoretical approach and participants), study process, and study limitations; (2) Findings and Discussion; (3) Conclusion; (4) Cited Literature; and (5) Appendices.

\section{Methods}

\section{Research design}

This mixed methods study used at its core a "qualitative" grounded theory (GT) methodology (Corbin and Strauss 2008), with an embedded "quantitative" component for comparison and contextual analysis.

\section{Grounded theory approach}

GT was used to (1) identify participants' main concerns (and behavior in addressing those concerns) related to the use and influence of information in developing legislative water policy; and (2) determine the degree to which specific criteria (RCL) influence the linkage between their decision making and implementation. GT is a qualitative approach that develops theories grounded in the data through systematic processes that follow logic and constant comparisons during analysis (Charmaz 2014).

Contrasted with positivist research, which can start with a theory to examine data, GT generally uses an inductive approach to construct a theory based on analysis of the evidence of raw data and observations. In this study, the participants were asked to answer both structured and open-ended unstructured questions that were formulated based on numerous notes and memos of interactions with congressional legislative staff over a number of years (Glaser 2001).

GT helps define related concepts through a multistage qualitative process (Fig. 3) that identifies important ideas and key word relationships (Glaser et al. 1968), together forming an integrated framework (Table 1) for explaining human outcomes (Creswell 2013, Charmaz 2014). While the staged process is roughly sequential, in practice, the researcher is continually forming and refining ideas by comparing and analyzing new data, impressions and conceptual insights together with existing coded key words, expressions and concepts from memos, notes, questionnaires, and interviews.

\section{Participants}

Considered as policy experts in their fields, congressional water policy legislative staff augment their understanding and knowledge of water policy legislation and inform their policy decision making by drawing on legal assessments, legislative historical context,

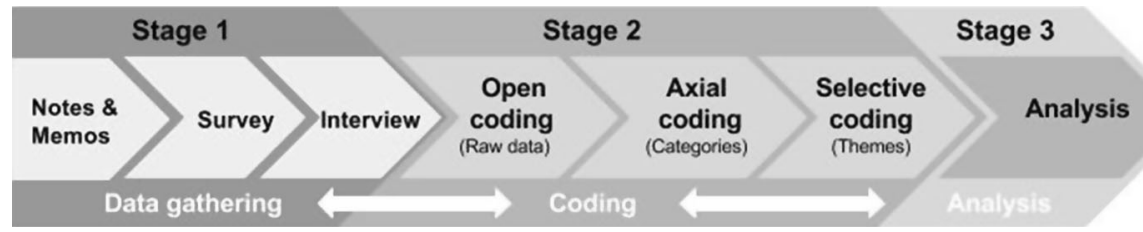

Fig. 3 Three dynamic stages and fundamental components of GT coding 
Table 1 Integrated grounded theory framework

\begin{tabular}{|c|c|c|}
\hline Stages & Components & Description \\
\hline $\begin{array}{l}\text { Stage 1: Data } \\
\text { gathering }\end{array}$ & $\begin{array}{l}\text { Raw data: (1) Notes \& } \\
\text { Memos } \\
\text { (2) Survey } \\
\text { (3) Interview }\end{array}$ & $\begin{array}{l}\text { Collection of the raw data used for analysis. The } \\
\text { structured data from the questionnaire are entered into } \\
\text { spreadsheet tables, and the unstructured data are } \\
\text { collected and formatted for coding in the next stage }\end{array}$ \\
\hline \multirow[t]{4}{*}{$\begin{array}{l}\text { Stage 2: Coding } \\
\text { data }\end{array}$} & $\begin{array}{l}\text { Analysis using the words, } \\
\text { phrases, and concepts }\end{array}$ & $\begin{array}{l}\text { The structured table data are aggregated and analyzed, } \\
\text { and the collected unstructured data are coded for } \\
\text { analysis }\end{array}$ \\
\hline & Open coding & $\begin{array}{l}\text { Collected raw data are segmented into conceptual key } \\
\text { words or short meaningful expressions and sequences } \\
\text { of words (Strauss and Corbin 1990; Corbin and Strauss } \\
\text { 2008) }\end{array}$ \\
\hline & $\begin{array}{l}\text { Axial coding (Identifying } \\
\text { Categories) }\end{array}$ & $\begin{array}{l}\text { Key words and expressions from the open coding process } \\
\text { are analyzed and grouped into categories related to the } \\
\text { phenomenon under study and associated "conditions, } \\
\text { context, actions/interactions strategies and } \\
\text { consequences" (Strauss and Corbin 1990) }\end{array}$ \\
\hline & $\begin{array}{l}\text { Selective coding } \\
\text { (Identifying Themes) }\end{array}$ & $\begin{array}{l}\text { Category data and development concepts from the axial } \\
\text { coding stage are analyzed in an inductive process of } \\
\text { comparing word sets to reduce individual bias, develop } \\
\text { word uniformity, and identify core conceptual patterns } \\
\text { and themes (Glaser et al. 1968) }\end{array}$ \\
\hline $\begin{array}{l}\text { Stage 3: Analysis } \\
\text { and } \\
\text { interpretation }\end{array}$ & Interpretation \& testing & $\begin{array}{l}\text { Utilizing the identified core themes, a theory is generated } \\
\text { about how an aspect of the social world "works." This } \\
\text { theory or explanation emerges from and is connected to } \\
\text { the reality that is being explained }\end{array}$ \\
\hline
\end{tabular}

diverse stakeholders, and policy analysis. As described earlier, while many congressional staff in the House and Senate cover water legislation related issues for their respective members, only a very small number of senior legislative staff are actually involved in drafting and developing water legislation.

In order to gain insight into the role and influence of scientific knowledge and other information and sources on congressional policy decision making and implementation, sixteen senior personal office and committee legislative staff from both political parties in the Senate and House were selected as members of a study group based on their own experiences and their respective congressional members' senior roles in legislative water resource policy. The participants came from diverse backgrounds in engineering, law, environment, history, and political science and had largely focused on water policy in their congressional positions.

At the time of this study, the first and second authors were both congressional staff in the US Senate with legislative policy and federal agency backgrounds. The first author-a senior legislative specialist with more than a decade of congressional and federal agency water policy and executive management experience-identified and recruited congressional staff colleagues and conducted the individual interviews. The second author-a specialist in innovation and organizational performance-structured the political and decision-making analysis. Both authors' backgrounds contributed to a contextual participant understanding and interpretative perspective in this GT-based research. 


\section{Study stages}

\section{Stage 1: data collection-preliminary observations, survey questionnaire, and interview}

The first stage of the GT process was to gather "raw" data to analyze. These data took the form of notes and memos, responses to a questionnaire, and personal interviews. An important raw data source for GT and the initial data collected were the notes and memos from meetings with many of the key staff over the years.

Each participant was then asked to complete an online survey questionnaire. The questionnaire was prepared and distributed, along with written guidelines, to the survey group. The group members were instructed to answer the questions from the perspective of their positions as legislative aides representing their congressional members and respective constituencies. Their answers were confidential and non-attributable; each respondent was only identified as a senior legislative staffer.

The survey questionnaire included both open-ended, fill-in-the-blank format questions, and structured questions consisting of selection lists, multiple choice, priority weighting, and Likert Scale rating $(1=$ Low; $5=$ High). The survey was divided into three parts: legislative priorities; actionable knowledge criteria; and legislative action. Participants were asked to identify their: (1) top-three priorities in the policy issue areas of federal water resources, flood, and drought; and (2) three highest and three lowest federal water resource mission agency priorities. In order to establish a baseline and to weight their other answers, survey participants were asked to determine the degree to which they perceived the information quality factors of relevance, credibility, and legitimacy to be important in the linking of policy-related information and legislative decision making and action. They were then asked to identify their top three information sources and rate each of eleven primary information sources according to how relevant, credible, and legitimate they viewed those sources to be in influencing their policy decision making and implementation. In this manner, the framework of RCL was imposed into the data collection.

Personal interviews were then individually conducted on-site in Washington, DC, giving each participant the opportunity to provide any necessary clarification on their answers to the questionnaire and elaborate on their ideas, thoughts, and insights. Before the interview commenced, an introduction to the study was given and consent for the interview confirmed. The basic interview protocol involved first sharing the anonymous aggregated responses from the questionnaire that all participants completed, and then asking each participant a set of common general questions based upon the questionnaire results. These interview questions were open-ended, addressing the participant's policy decision-making and legislative water policy experiences and his or her member's water resource decisionmaking process. The process of utilizing survey questionnaires and interviews was based on grounded theory research principles. During the interviews, participants were encouraged to speak naturally and unprompted about their water policy work, decision-making process and priorities and share perspectives and insights into their policy decision-making experiences.

The interviews were scheduled over an approximate two-month time frame, each interview averaging between 30 and $45 \mathrm{~min}$ in duration. Roughly half of the interviewed participants consented to being audio recorded, while the remainder preferred to not be recorded for reasons of confidentiality and anonymity. Notes, transcriptions, questionnaire responses, and audio recordings were all consolidated as the "raw data" for processing 
using the GT qualitative coding analysis. This study was reviewed and deemed to be exempt from human subjects research through an institutional review board (IRB) process, receiving a study waiver IRB-ID\#982099-2 from The University of Alaska Fairbanks, Office of Research Integrity.

\section{Stages 2 and 3: data coding and analysis}

After the interviews were completed, the responses were collected, and the results were aggregated and coded from both the questionnaire and the interview process. Structured questionnaire results were aggregated in analytical matrices to generate decision-making characteristics, following a methodology described by Charmaz (2014). Unstructured data were coded through the following three-step process: open, axial, and selective. The procedural framework of the initial coding process and comparison of key words from the three coding processes were used to create the uniform themes of the study.

Open coding - In the first step, the raw data from the previous notes, memos, survey questionnaire and interviews were analyzed (based on the frequency of occurrences) to identify preliminary key words and expressions to support the axial and selective coding processes following methods described by Saldaña (2013). The structured questionnaire data were collected and used in an analysis matrix to generate decision-making characteristics. Qualitative data analysis software ATLAS.ti was used to code the responses and analyze the codes. The raw data for coding consisted of approximately 3000 coded key words and phrases that then served as the data processed in the next step of categorization.

Axial coding-During the second step, the defined key words and expressions were aggregated, analyzed, and grouped into categories related to the study questions and associated "conditions, context, actions/interactions strategies and consequences" (Strauss and Corbin 1990). In order to categorize the raw data, the words and phrases were counted, and associations and relationships were identified and grouped into categories of similar meanings. For example, key words, such as "flood, flooding, rising water, inundation, over the bank" and "relationships, networks, constituents, stakeholders, shareholders," were grouped into categories of similar meanings.

Selective coding - The third step of the analysis process assimilated and built on results from steps one and two by determining connections between the key words and phrases from the open coding process, and using the categorization matrix from the axial coding process to identify or describe overall themes. These themes reflected the views, attributed importance, concepts and interests communicated by the participants.

Following this step, the authors solicited and received feedback from participants in order to validate the classifications and themes identified in the selective coding process and verify that these selections reflected and were consistent with participant perspectives.

Stage 3 of the process consisted of analyzing the core themes from the selective coding process and generating a theory that explained legislative staff participants' behavior and concerns related to water policy and the decision-making process. This "general, abstract theory of process, action, or interaction [was] grounded in the views of participants in a study" and used an inductive process rendering generalizations from specific observations (Creswell 2014).

\section{Limitations}

With the study group limited to sixteen participants, the authors do not claim that the results represent overall congressional legislative water policy priorities or views, or even 
those of all senior legislative staff working on water policy issues in the US House and Senate during this time period. However, at the time of this research, these sixteen were considered by the authors to represent approximately $60-70 \%$ of senior staff that were instrumental in the development of federal legislative water policy, and their perspectives provided the insights sought by the study.

As no qualitative research method is completely free from preconceptions and bias in data gathering, interpretation and analysis, there is an inherent individual and contextual subjectivity and bias that the authors brought to the study based on their own experiences in research and policy and professional relationships with the participants. However, this is consistent with the focus of GT-the development and use of an interpretative lens by researchers for thinking about and conceptualizing grounded data, the process resulting in statements about how people think, behave, and resolve their concerns. With this as the objective, proponents argue that GT should be judged by the relevance, fit, workability and flexibility of its methodology and results (Glaser et al. 1968; Glaser1978).

\section{Results and discussion}

The analytical process employed both inductive and deductive approaches. Based on their experience with legislative policy, staff decision making, and knowledge of the study participants, the authors identified patterns of information processing within an information quality criteria framework (RCL) describing the transfer of information across sciencepolicy boundaries and the linking of policy decision making to action. In the survey questionnaire, participants were queried as to their assessment of the perceived influence of these criteria on their decision making and policy action, and their responses were analyzed deductively. The interviews, however, utilized an unstructured and open-ended format whereby general questions were posed, and participants were encouraged to talk freely about common issue areas and the role of information in legislative policy decision making and behavior.

GT method coding processes were used to analyze raw data, from which both conceptual categories and core themes emerged. From the raw data, approximately 3000 words were collected and consolidated, producing approximately 936 key coded word concepts or phrases selected from open coding integration. Using axial coding methods, 53 categories were constructed using 278 descriptive key word concepts or expressions. Described below, selective coding was applied to these axial coded categories, from which three themes emerged.

Both the structured results from the survey and the coded results from the unstructured data were analyzed using an inductive approach. The information quality criteria framework of RCL served as a useful interpretative lens - and was explored as a potential heuristic tool-in identifying potential relational correlations in the patterns, categories, and themes that emerged from the participant data.

\section{Themes}

Three interrelated conceptual themes (Fig. 4) emerged, based on percentage of total coded participant key words and expressions, which reflected interests and priorities of the legislative staff participants: (1) Developing a trusted relationship-information network 
Fig. 4 Conceptual themes developed from the "selective coding" process

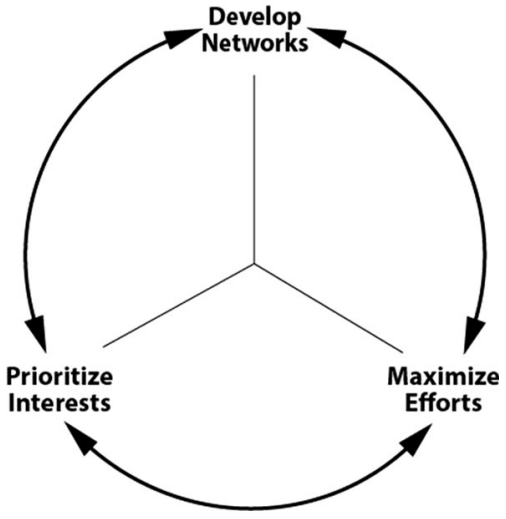

(DN)-49.6\%; (2) Prioritizing relevant stakeholder interests (PI)-33.8\%; and (3) Maximizing efforts to achieve desired results (ME) $-16.6 \%$.

Table 2 depicts results from the phased coding process and highlights the three conceptual themes that emerged from the raw data research analysis. The first column provides

Table 2 Illustrated examples from GT coding process

\begin{tabular}{|c|c|c|}
\hline Open coding (Raw data) & $\begin{array}{l}\rightleftarrows \text { Axial Coding } \rightleftarrows \\
\text { (Categories) }\end{array}$ & Selective coding (Themes) \\
\hline
\end{tabular}

"Finding the right people" Stakeholder buy-in

"Stakeholders"

"Relevant groups"

"Partner relationships"

"Knowing who to trust"

"Constituent relations"

"Working groups"

"Developing solutions with people"

\section{"Create policy mandates"}

"Select practical outcomes"

"Highlight key effects of policies"

"Select cost vs. results of polices"

"Record areas of gaps/holes"

"Place in order"

"Pros and Cons"

"Meet w/ state personnel"

"Governor's top action items"

"local agency responsibilities"

"Residential impact of policy"

"Capability effort and conclusions "

"Make most of policy" solutions associations

Develop participant engagement
Develop Relationship-Information

Networks (DN)

$49.6 \%$ of total key words/expressions

Data awareness networks

Looking at partnerships

Working with others for

Improve understanding
Order of affordability \& costs Imperative criteria of solutions Maximize political expectations

Organize assumptions

Rank consequences

Balance needs vs. wants

Capitalize on policy benefits

Apply support outcomes results

Maximize Efforts (ME)

$16.6 \%$ of total key words/expressions

Prioritize Interests (PI)

$33.8 \%$ of total key words/expressions

Utilize local development

Progress in information results

Advancement in knowledge outcome

Trusting results and effects

Improve outcome understanding 
several sample raw data key words and expressions collected during the gathering phase. The middle column lists the categories that were derived from axial coding of the concepts and ideas from the open coding step. Lastly, the third column lists themes that emerged from the categories during the selective coding stage, along with percentage of raw data falling into the respective themes.

\section{Developing relationship-information networks (DN)}

While all three conceptual themes were shared by many of the participants, the most commonly shared theme that emerged from participant interviews was the critical importance of developing and cultivating the personal relationship-information networks essential for staff success. Study results confirmed the findings of Romzek and Utter (1997) that information is the primary currency of congressional staff interactions, and that the primary way that staff gather information and develop coalitions, and influence is through networks. Staff often receive or solicit information from their work relationships and informal networks (professional friendships with other staffers, second-tier professional circles, and relationships built on long-term community networks, etc.). Establishing knowledge networks with a wide range of congressional and outside sources to obtain relevant policy-related information, together with developing and maintaining a reputation as a credible and trustworthy source, is essential for any staff that wants to be successful in his or her job within the legislative process.

Depending on the degree of trustworthiness of these networks, information received from and shared with network contacts is often as influential, or more so, than information from most other sources. These networks are important not only as direct resources for information, but also indirectly for such purposes as political alliances, collaboration, negotiating partnerships, social and political cohesion, and for advancing personal career interests. These networks are also useful for achieving stakeholder buy-in for policy positions, communicating knowledge, assessing credibility and trust, and developing good working relationships.

Since networks are generally formed on the basis of perceived functional utility and political interests, the most effective networks tend to include reciprocal informationsharing relationships with sources from competing stakeholder groups (e.g., political parties) that are useful for drafting legislation, political insight, negotiation, and strategic cooperation.

Relational information networks are very diverse, reflecting the personalities and interests of staff members, and can range from highly formal and structured professional relationships to casual or informal trust relationships within personal or social networks. For staff, individual relationships in networks or institutions are generally more important than the actual organization or network to which those individuals belong. At the same time, the attributed value and influence of those organizations with staff members often reflect their personal experiences with specific individuals in those organizations.

Networks are also critical as sources and social interfaces of knowledge. Staff rely heavily upon trusted relationship-information networks for both developing and enhancing their own frames of reference and decisions, and for reducing the equivocality they experience in the face of competing frames of references from multiple credible information sources. 


\section{Prioritizing stakeholder interests (PI)}

The second general conceptual theme that emerged was the goal of effectively prioritizing stakeholder interests and aligning efforts and resources to achieve these priorities. This theme emerged from such recurring concepts (axial coded as "categories") as calculating cost-benefits (financial, political, social, etc.) of competing interests, determining critical paths to success or failure, weighing political expectations against degrees of fulfillment and their consequences, balancing needs versus wants, capitalizing on policy benefits, etc.

The various roles that legislative staff play influence their perception, balancing, and prioritization of stakeholder interests, as well as the development of their information networks. Observations and feedback from information networks, in turn, help shape the staff's perception and prioritization of these interests and the actions those interests influence.

Coding analysis of legislative notes, memos, survey answers, and interview transcripts indicates that the top five overall water policy priorities of the sixteen participants were: (1) water infrastructure; (2) water policy regulatory reform; (3) water quality; (4) drought; and (5) flooding. Priorities were also listed within the areas of water resources, drought, and flood. As an example, within the area of flood issues, participants listed: (1) flood insurance; (2) floodplain mapping; and (3) flood control (infrastructure) as their top three policy issue priorities. Issue priorities are usually reflections of the legislative staff's cognitive ranking of stakeholder interests in their multiple principal-agent roles.

Staff see themselves as balancing multiple principal-agent roles in which they are either the agent (i.e., to their member or other stakeholders) or the principal (i.e., to science researchers or other information providers). Applying the principal-agent model lens to congressional staff requires consideration of multiple principals and agents and recognition of the risk that staff, as expert agents with their own policy agendas and personal interests, may have interests and agendas that overlap or conflict with those they represent (Romzek 2000). Staff decisions and behavior are influenced and constrained by relationships of accountability with multiple stakeholders, not only with their respective members of Congress (the primary stakeholder and accountability relationship), but indirectly with any group that potentially affects the primary stakeholder, as well as with their own personal agenda and career interests. Problems can arise from either an unevenness or asymmetry of information-when the agent has more information than the principal—and if and when the agent has different or competing interests.

Policy action by senior legislative staff is largely driven by short and long-term priorities that dynamically evolve according to unfolding events and new information and perceptions of personal and stakeholder interests. As such, long-term policy objectives and interests of one or more legislators may be subordinated in the short-term to perceptions of self-interest and the shifting priorities of stakeholders and political or ideological considerations. However, regardless of the degree to which policy action is perceived to be based on the objective merits of scientific information, the influence of information on policy behavior, in pursuit of personal and stakeholder priorities is still largely dependent upon policymakers' perceptions of the content's RCL attributes.

\section{Maximizing efforts-results (ME)}

The third conceptual theme that emerged was the commonly shared goal of maximizing personal efforts to achieve desired results. This theme emerged from such recurring 
concepts as the desire to not waste time, but to efficiently develop stakeholder buy-in, apply support, advance programs, utilize knowledge more effectively, knowing what sources to trust, etc.

Due to multiple competing priorities and many demands on their time, staff often feel that their ability to achieve their objectives and goals is significantly constrained. Many of the projects and tasks they are involved in have many players and levels of complexity and vested interests, often resulting in failure to achieve the desired results. For example, staff expressed frustration at having made many attempts over the years to craft and pass various pieces of water resources legislation, only to successively watch those efforts come to naught as the bills were killed by elements and events outside their control.

\section{Situating the GT results within the RCL framework}

In each of the three discussed theme areas, staff intuitively selected and utilized heuristics in determining whether information was relevant to their various principal-agent roles (e.g., matching perceived policy information needs), whether the relevant information was credible enough to be a factor in decision making, and whether relevant and credible information met minimal thresholds of legitimacy in order to influence policy action. Participants confirmed that information quality criteria were important in influencing to what degree they utilized that information in decision making, even though few, if any, of the participants indicated that they were consciously or metacognitively aware of their information relationship roles or the processes they employed in making decisions or taking action. A common participant response was "I've never actually thought about how I make decisions using any type of methodology or what type of structural concept influences them; I just do it." The arrows in the Fig. 5 illustrate the interrelationship of the three themes.

Throughout the various stages of the process, senior staffers are constantly evaluating new and often conflicting pieces of information. The information that they act upon and communicate with their members, or the stakeholder interests the members represent, is largely determined by the staff's assessment of the relevance, credibility and legitimacy of that information. Likert scale results from questionnaire ratings showed that the study participants judged all three quality criteria to be important in determining the degree of influence on their decision making and policy action, with credibility scoring the highest (4.6/5), followed by relevance as a close second (4.3/5) and then legitimacy (3.9/5).

Fig. 5 RCL dynamic and theme areas. Dynamic interaction between information heuristic influences (RCL) linking decision making and action in the three conceptual theme areas

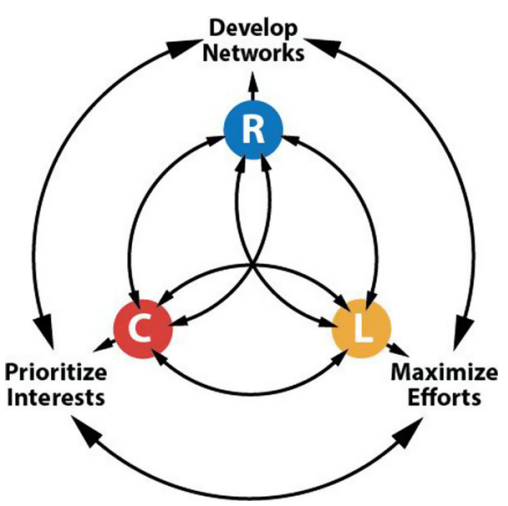


Presented with a list of eleven sources of policy-related information, survey participants were then asked to evaluate each information source, using a Likert scale of 0-5 $(0=$ Not Applicable/Don't know; 1 = Very Low; 2 = Low; $3=$ Average; $4=$ High; $5=$ Very High), according to how relevant, credible (scientific plausibility and technical adequacy), and legitimate (unbiased and procedurally fair) the participants perceived the sources to be (on average) in forming or changing their water resource policy decisions and taking legislative action on those decisions. The results (Table 3) indicate that overall the

Table 3 Rating of information sources according to influence of quality criteria

\begin{tabular}{|c|c|c|c|c|c|}
\hline Information source & $\begin{array}{l}\text { Information } \\
\text { quality criteria }\end{array}$ & $\begin{array}{l}\text { Individual } \\
\text { criteria avg } \\
(1-5)\end{array}$ & $\begin{array}{l}\text { Individual } \\
\text { criteria } \\
\text { ranking }\end{array}$ & $\begin{array}{l}\text { Cum. } \\
\text { criteria } \\
\text { avg. }\end{array}$ & $\begin{array}{l}\text { Information } \\
\text { quality } \\
\text { ranking }\end{array}$ \\
\hline \multirow[t]{3}{*}{ Committee staff contacts } & Relevance & 4.69 & 1 & \multirow[t]{3}{*}{4.17} & \multirow[t]{3}{*}{$\# 1$} \\
\hline & Credibility & 4.06 & 2 & & \\
\hline & Legitimacy & 3.75 & 2 & & \\
\hline \multirow[t]{3}{*}{ State constituent experts } & Relevance & 4.50 & 4 & \multirow[t]{3}{*}{4.00} & \multirow[t]{3}{*}{$\# 2$} \\
\hline & Credibility & 3.88 & 2 & & \\
\hline & Legitimacy & 3.63 & 3 & & \\
\hline \multirow{3}{*}{$\begin{array}{l}\text { State Governor's office } \\
\text { experts }\end{array}$} & Relevance & 4.38 & 3 & \multirow[t]{3}{*}{3.88} & \multirow[t]{3}{*}{ \#3 } \\
\hline & Credibility & 3.81 & 5 & & \\
\hline & Legitimacy & 3.44 & 4 & & \\
\hline \multirow{3}{*}{$\begin{array}{l}\text { CRS and LOC briefing } \\
\text { summaries/overviews }\end{array}$} & Legitimacy & 4.06 & 1 & \multirow[t]{3}{*}{3.85} & \multirow[t]{3}{*}{$\# 4$} \\
\hline & Credibility & 3.94 & 3 & & \\
\hline & Relevance & 3.56 & 8 & & \\
\hline \multirow{3}{*}{$\begin{array}{l}\text { Outside source water } \\
\text { policy scientist experts }\end{array}$} & Credibility & 4.25 & 1 & \multirow[t]{3}{*}{3.73} & \multirow[t]{3}{*}{ \#5 } \\
\hline & Relevance & 3.50 & 9 & & \\
\hline & Legitimacy & 3.44 & 5 & & \\
\hline \multirow{3}{*}{$\begin{array}{l}\text { Outside source water } \\
\text { policy legal experts }\end{array}$} & Credibility & 3.75 & 6 & \multirow[t]{3}{*}{3.56} & \multirow[t]{3}{*}{ \#6 } \\
\hline & Relevance & 3.69 & 5 & & \\
\hline & Legitimacy & 3.25 & 6 & & \\
\hline \multirow{3}{*}{$\begin{array}{l}\text { Federal executive branch } \\
\text { staff }\end{array}$} & Relevance & 3.69 & 7 & \multirow[t]{3}{*}{3.31} & \multirow[t]{3}{*}{ \#7 } \\
\hline & Credibility & 3.25 & 8 & & \\
\hline & Legitimacy & 3.00 & 7 & & \\
\hline \multirow[t]{3}{*}{ Hearing testimony } & Relevance & 3.94 & 4 & \multirow[t]{3}{*}{3.25} & \multirow[t]{3}{*}{$\# 8$} \\
\hline & Credibility & 3.19 & 9 & & \\
\hline & Legitimacy & 2.63 & 9 & & \\
\hline \multirow{3}{*}{$\begin{array}{l}\text { Think-tank briefings, } \\
\text { seminars, and } \\
\text { workshops }\end{array}$} & Credibility & 3.31 & 7 & \multirow[t]{3}{*}{3.15} & \multirow[t]{3}{*}{$\# 9$} \\
\hline & Relevance & 3.25 & 11 & & \\
\hline & Legitimacy & 2.88 & 8 & & \\
\hline \multirow[t]{3}{*}{ Lobbying groups } & Relevance & 3.69 & 6 & \multirow[t]{3}{*}{2.94} & $\# 10$ \\
\hline & Credibility & 2.69 & 10 & & \\
\hline & Legitimacy & 2.44 & 10 & & \\
\hline Personal office staff & Relevance & 3.31 & 10 & 2.56 & $\# 11$ \\
\hline contacts & Credibility & 2.31 & 11 & & \\
\hline & Legitimacy & 2.06 & 11 & & \\
\hline
\end{tabular}


Table 4 Information sources ranked by importance and utilization

\begin{tabular}{llc}
\hline Information source & \# Selected as top 3 & Rank \\
\hline Committee staff & 9 & 1 \\
State Governor's office experts & 8 & 2 \\
State constituent experts & 6 & 3 \\
Personal office staff & 5 & 4 \\
CRS and LOC & 5 & 4 \\
Federal Executive branch staff & 4 & 5 \\
Outside source water policy scientist experts & 4 & 5 \\
Lobbying groups & 3 & 6 \\
Outside source water policy legal experts & 2 & 7 \\
Hearing testimony & 1 & 8 \\
Think-tank briefings, seminars, and workshops & 1 & 8 \\
Other (please specify) & 0 & - \\
\hline
\end{tabular}

Ranking of "top 3" sources considered most important and utilized for decision making and policy action

surveyed staff rated the top three most influential information sources as "committee staff contacts" (avg 4.2/5), "State constituent experts" (4.0/5), and "State governor's office experts" (3.9/5). The three lowest rated sources (based on accumulated averages) were "Think-tanks/nonpartisan policy research groups" (3.2/5), "Lobbying groups" (2.9/5), and "Personal office staff in other congressional offices" (2.6/5).

The results from these individual ratings were compared to the results (Table 4) of participants' listing of the top three sources of information (selected from the list of eleven) they considered most important and utilized most often in making and acting upon their legislative policy decisions. The three sources that had the highest aggregate scores in terms of RCL ratings (Table 3) were also the three sources rated as the most important and utilized (Table 4). One of the three sources that had the lowest aggregate scores in terms of RCL ratings ("Think-tank briefings, seminars, and workshops") (Table 3) was also ranked last in the top-three ranking of the eleven sources in terms of being considered important and useful (Table 4).

\section{Discussion}

As policymakers address concerns and pursue objectives, results from the study suggest that the degree to which policy information influences their policy actions is largely determined by their perceptions of the information content's RCL attributes. Staff, in their multiple principal-agent roles, value and utilize policy-related information in relation to three primary themes of concerns and desired outcomes: network development, personal and stakeholder priorities, and maximizing efforts. Concerns and objectives are dynamically influenced by information content and, at the same time, largely determine what content is processed and or influences policy decisions and action.

The application of RCL to these themes provides an interpretative lens for understanding policy decision making with practical implications for both policymakers and information content providers. Policymakers gain insight into their own approaches to processing information and can communicate to content providers what information and 
messaging are likely to be seen as useful in shaping their attitudes and beliefs and influencing policy actions. This interpretative lens and insight also have implications for content providers in terms of guiding research, messaging and interaction with policymakers whom they are seeking to influence. Furthermore, this lens can also be useful in establishing a deliberative framework for the interface between science information and policymakers.

\section{Conclusion}

This paper seeks to provide insight into the policy priorities of senior legislative staff and their respective congressional members in the US House and Senate, as well as provide an interpretative lens for understanding the content sources, framing and actualization of specific knowledge used both in policy formation and action. The paper discusses the results of a grounded theory research study of senior legislative staff in the area of federal water policy and examines what factors influence the linkages between policy-related information, decision making, and legislative action.

Various authors in science-policy literature have argued that science-related information must meet minimum thresholds of the three quality criteria of RCL (as perceived and attributed by the information recipients) in order for that information to transfer across the science-policy boundary and influence policy decision making and behavior. This study used RCL as a framework to discover: (1) to what degree actual decision makers felt these criteria were important in bridging information boundaries to influence policy; and (2) whether or not and/or to what degree these criteria (whether or not the policymakers defined the RCL concepts with those labels) or similar concepts were used by policymakers as intuitive or rational heuristics in judging whether information influenced their decisions.

The information quality criteria framework of RCL can be useful as decision-making tools of legislative policymakers and for transferring knowledge across science-policy action boundaries, but a full understanding of the dynamics of information processing must take into account the multiple principal-agent roles that staff play. The common priorities for legislative staff of (1) developing trusted relationship-information networks; (2) prioritizing relevant stakeholder interests; and (3) maximizing efforts to achieve desired results can be understood within the RCL framework as a way to bridge the gap between water science and water policy.

Study results suggest that the application of RCL to these priority themes has practical implications for both policymakers and information content providers. Policymakers gain insight into their own information priorities and processing and can use this insight in both more effectively processing large amounts of policy information and in guiding the content input and messaging from information content providers. Content providers can also use this insight to inform their research, messaging, and interaction with policymakers that they are seeking to influence.

Open Access This article is distributed under the terms of the Creative Commons Attribution 4.0 International License (http://creativecommons.org/licenses/by/4.0/), which permits unrestricted use, distribution, and reproduction in any medium, provided you give appropriate credit to the original author(s) and the source, provide a link to the Creative Commons license, and indicate if changes were made. 


\section{References}

Allin, B. (2008). An examination of the United States' system of water management. 598 Policy Report, Environment Canada.

Bauler, T. (2012). An analytical framework to discuss the usability of (Environmental) indicators for policy. Ecological Indicators, 17, 38-45.

Cash, D. W., Clark, W. C., Alcock, F., Dickson, N. M., Eckley, N., Guston, D. H., et al. (2003). Knowledge systems for sustainable development. Proceedings of the National Academy of Sciences of the United States of America, 100(14), 8086-8091. https://doi.org/10.1073/pnas.1231332100.

Cash, D., Clark, W. C., Alcock, F., Dickson, N., Eckley, N., \& Jäger, J. (2002). Salience, credibility, legitimacy and boundaries: Linking research, assessment and decision making. KSG faculty research working papers series RWP02-046, November 2002. SSRN Electronic Journal SSRN Journal. https:// doi.org/10.2139/ssrn.372280.

Charmaz, K. (2014). Constructing grounded theory: A practical guide through qualitative analysis. London: Sage Publications.

Christian-Smith, J., Gleick, P. H., \& Cooley, H. (2011). U.S. water policy reform (chapter 7). The World's Water 7. https://doi.org/10.5822/978-1-59726-228-6_7

Clark, W. C., Kerkhoff, L. V., Lebel, L., \& Gallopin, G. C. (2016). Crafting usable knowledge for sustainable development. Proceedings of the National Academy of Sciences, 113(17), 4570-4578. https:// doi.org/10.1073/pnas.1601266113.

Cody, B. A., Schneider, J., Tiemann, M., \& Relf, G. (2012). Selected federal water activities: Agencies, authorities, and congressional committees. Congressional Research Service. Report No. RLR42653. OpenCRS. Web. 8 Jan. 2017.

Congressional Research Service. (2016a). House of representatives staff levels in member, committee, leadership, and other offices, 1977-2016 (September 13, 2016). Report No. R43947. OpenCRS. Web. 8 Jan. 2017.

Congressional Research Service. (2016b). Senate staff levels in member, Committee, Leadership, and Other Offices, 1977-2016 (September 13, 2016). Report No.R43946. OpenCRS. Web. 8 Jan. 2017.

Corbin, J., \& Strauss, A. (2008). Basics of qualitative research (3rd edn.) Techniques and procedures for developing grounded theory. https://doi.org/10.4135/9781452230153.

Creswell, J. W. (2013). Qualitative inquiry and research design: Choosing among five approaches. Los Angeles: SAGE Publications.

Creswell, J. W. (2014). Research design: Qualitative, quantitative, and mixed methods approaches. Los Angeles: Sage.

Gerlak, A. K. (2006). Federalism and U.S. water policy: lessons for the twenty-first century. Publius: The Journal of Federalism, 36, 231-257.

Glaser, B. G. (1978). Theoretical sensitivity: Advances in the methodology of grounded theory. Mill Valley, CA: Sociology Press.

Glaser, B. G. (2001). The grounded theory perspective: Conceptualization contrasted with description. Mill Valley, CA: Sociology Press.

Glaser, B. G., Strauss, A. L., \& Strutzel, E. (1968). The discovery of grounded theory, strategies for qualitative research. Nursing Research, 17, 364.

Gluck, A. R., \& Bressman, L. S. (2014). Statutory interpretation from the inside-an empirical study of congressional drafting, delegation, and the canons: Part I. Stanford Law Review, 66(4), 725-801.

Guston, D. H. (1999). Stabilizing the boundary between us politics and science: The role of the office of technology transfer as a boundary organization. Social Studies of Science, 29, 87-111.

Heink, U., Marquard, E., Heubach, K., Jax, K., Kugel, C., Neßhöver, C., et al. (2015). Conceptualizing credibility, relevance and legitimacy for evaluating the effectiveness of science-policy interfaces: Challenges and opportunities. Science and Public Policy, 42, 676-689.

Lemos, M. C., Kirchhoff, C. J., \& Ramprasad, V. (2012). Narrowing the climate information usability gap. Nature Climate Change, 2, 789-794.

McNie, E. C. (2007). Reconciling the supply of scientific information with user demands: An analysis of the problem and review of the literature. Environmental Science \& Policy, 10, 17-38.

Meinke, H., Nelson, R., Kokic, P., Stone, R., Selvaraju, R., \& Baethgen, W. (2006). Actionable climate knowledge: From analysis to synthesis. Climate Research, 33, 101-110.

Neuman, J. (2010). Are We There Yet? Weary travelers on the long road to water policy reform. Natural Resources Journal, 211(139): 139-166. https:/www.copyright.com/ccc/basicSearch.do?

Nourse, V., \& Schacter, J. S. (2002). The politics of legislative drafting: A congressional case study. In New York University Law Review (vol. 77, pp. 575-623). University of Wisconsin Legal Studies Research Paper Series Archival Collection. https://ssrn.com/abstract=1527043 
Romzek, B. S. (2000). Accountability of congressional staff. Journal of Public Administration Research and Theory, 10, 413-446.

Romzek, B. S., \& Utter, J. A. (1996). Career dynamics of congressional legislative staff: Preliminary profile and research questions. Journal of Public Administration Research and Theory, 6, 415-442.

Romzek, B. S., \& Utter, J. A. (1997). Congressional legislative staff: Political professionals or clerks? American Journal of Political Science, 41, 1251.

Sabatier, P., \& Whiteman, D. (1985). Legislative decision making and substantive policy information: Models of information flow. Legislative Studies Quarterly, 10, 395.

Saldaña, J. (2013). The coding manual for qualitative researchers. Los Angeles: SAGE Publications.

Shobe, J. (2014). Intertemporal statutory interpretation and the evolution of legislative drafting. Columbia Law Review, 114(4), 807-877.

Strauss, A. L., \& Corbin, J. M. (1990). Basics of qualitative research: Grounded theory procedures and techniques. Newbury Park, CA: Sage Publications. 